\title{
Anisotropy of acousto-optic figure of merit at the collinear acousto-optic diffraction in hexagonal $\mathrm{CdS}$ crystals
}

\author{
Mys O., Martynyuk-Lototska I., Adamenko D., Kostyrko M. and Vlokh R. \\ Vlokh Institute of Physical Optics, 23 Dragomanov Street, 79005 Lviv, Ukraine, \\ mys@ifo.lviv.ua
}

Received: 13.07 .2018

\begin{abstract}
In the present work we analyze anisotropy of the acoustic properties and acousto-optic figure of merit (AOFM) in CdS crystals at the collinear acousto-optic interactions. We show that the anisotropy of AW velocity is very small so that the AOFM anisotropy is mainly caused by the anisotropy of effective elastooptic coefficients. The obliquity angle and the angle of deviation of polarization of the acoustic waves (AWs) from purely longitudinal and transverse types are found. The geometries of collinear diffraction at which the maximal AOFM values are reached are determined. It is found that the absolute maximum, $M_{2}=86.26 \times 10^{-15} \mathrm{~s}^{3} / \mathrm{kg}$, is peculiar for the type VIII of interactions with the AW $\mathrm{QT}_{1}$ with the frequency $f=49 \mathrm{MHz}$, which is polarized along the $Z$ axis. In this case the interaction plane is rotated by the angle $\varphi_{Z}=45 \mathrm{deg}$, and both the light and AW propagate along the $X$ axis lying in the $X Y$ plane. The maximal AOFM values and the appropriate interaction geometries are also determined for the particular case of collinear AO diffraction at the $\mathrm{AWs} \mathrm{QL}$ and $\mathrm{QT}_{2}$. These values are equal to $4.41 \times 10^{-15}$ and $26.25 \times 10^{-15} \mathrm{~s}^{3} / \mathrm{kg}$ for the interactions with the $\mathrm{AWs} \mathrm{QL}$ and $\mathrm{QT}_{2}$, respectively.
\end{abstract}

Keywords: CdS crystals, optical vortex, acoustic vortex,acousto-optic diffraction, acousto-optic figure of merit, collinear diffraction, anisotropy

PACS: 42.25.Fx, 42.50.Tx, 42.79.Jq, 47.32.cb

UDC: $535.42,535.012 .2,534.2$

\section{Introduction}

CdS crystals are representatives of wurtzite minerals [1] and belong to the point symmetry group $6 \mathrm{~mm}$ [2]. These crystals are transparent at the optical wavelengths $0.52-16 \mu \mathrm{m}$ [3], i.e. in the long-wavelength region of the visible spectral range and in a wide part of the infrared. Cadmium sulfide is among well-known optical materials. In particular, it has been characterized from the viewpoints of its dielectric, elastic, conductivity [4, 5], electrooptic and nonlinear optical characteristics [6-9]. CdS can be efficiently used in integrated optical devices in their planar and channel versions [10-12]. It is known that acousto-optic figure of merit (AOFM) for CdS is equal to $12.1 \times 10^{-15} \mathrm{~s}^{3} / \mathrm{kg}$ [13] for the case of interactions with the longitudinal acoustic wave (AW) that propagates in the plane perpendicular to crystallographic axis $c$. This AOFM value is comparable with that typical for such a well known acousto-optic (AO) material as $\mathrm{LiNbO}_{3}$ [14-16]. However, the acoustic attenuation for the CdS crystals is somewhat higher. It reaches $2 \mathrm{~dB} / \mathrm{cm}$ at the frequency $0.1 \mathrm{GHz}$ for the case of longitudinal AWs and $20 \mathrm{~dB} / \mathrm{cm}$ at $0.5 \mathrm{GHz}$ for the case of transverse AWs propagating perpendicular to the $c$ axis [17]. Nonetheless, waveguide AO Bragg modulators have been successfully fabricated on the basis of CdS [18]. It has been shown experimentally that the acoustic power necessary for the complete transfer of optical power out from the zeroth diffraction order is equal to $15 \mathrm{~mW}$ at the operation frequency $10 \mathrm{MHz}$ of the 
modulator. Thus, CdS can be efficiency used for the AO operation of light with the integrated optical waveguide structures.

Although the acoustic and elastooptic properties of CdS have been studied in much detail $[19,20]$, anisotropy of their AOFM has not yet been analyzed. This analysis would be important since it could reveal the geometries of AO interactions characterized by still higher AOFM values. In particular, this concerns a collinear diffraction type which is a basis for the tunable AO filters [21-25]. The aim of this work is to analyze the anisotropy of AOFM for the collinear type of AO diffraction in the CdS crystals.

\section{Background of the analysis}

CdS crystals are optically uniaxial and negative at the room temperature $n_{o}=2.467$ and $n_{e}=2.484$ [26]). Like any material belonging to the point symmetries $6 / \mathrm{mmm}, 622, \overline{6} \mathrm{~m} 2$ and $6 \mathrm{~mm}, \mathrm{CdS}$ is characterized by the elastic stiffness tensor that contains six independent components $\left(C_{11}=C_{22}\right.$, $C_{12}=C_{21}, C_{13}=C_{23}=C_{31}=C_{32}, C_{33}, C_{44}=C_{55}$ and $C_{66}=\left(C_{11}-C_{12}\right) / 2$, where a standard Voigt notation is accepted). Its elastooptic tensor has seven independent coefficients $p_{11}=p_{22}$, $p_{12}=p_{21}, p_{13}=p_{23}, p_{31}=p_{32}, p_{33}, p_{44}=p_{55}$ and $p_{66}=\left(p_{11}-p_{12}\right) / 2$ [27]. In our calculations we use the elastic-stiffness coefficients of CdS obtained in the work [19] $\left(C_{11}=84.31, C_{12}=52.08\right.$, $C_{13}=45.67, C_{33}=91.83$ and $C_{44}=14.58 \mathrm{GPa}$ ) and the elastooptic coefficients taken from Ref. [20] $\left(p_{11}=-0.142, p_{12}=-0.066, p_{13}=-0.057, p_{31}=-0.045, p_{33}=-0.20, p_{44}=-0.099\right.$ and $\left.p_{66}=-0.038\right)$. All the optical data refers to the light wavelength $632.8 \mathrm{~nm}$. The relations of the crystallographic axes $a$, $b$ and $c$ and the axes $X, Y, Z$ of optical indicatrix ellipsoid are as follows: $Z\|c\|[0001]$, $X\|a\|[2 \overline{1} \overline{1} 0], b \|[01 \overline{1} 0]$, whereas the $Y$ axis is perpendicular to the $a c$ plane.

The obliquity angles of AWs in the principal planes can be calculated using the relation [28]

$$
\tan (\Delta)=\frac{1}{v(\Theta)} \frac{\partial v}{\partial \Theta}
$$

where $\Delta=\Theta-\psi, \Theta$ is the angle between the principal axis (e.g., the $X$ axis) and the AW vector, $\psi$ the angle between the same axis and the acoustic energy flow direction, and $v(\Theta)$ the AW velocity specified for the propagation direction under interest. Finally, the changes $v(\Theta)$ in the AW velocity caused by changing propagation direction are readily obtained from the Christoffel equation. The same is true of the angle between the AW vector and the displacement vector [2]. We have calculated this angle for the cases of quasi-longitudinal (QL) AWs propagating respectively in the $X Z, Y Z$ and $X Y$ planes:

$$
\begin{aligned}
& \zeta_{X Z}=\frac{1}{2} \arctan \frac{\left(C_{13}+C_{44}\right) \sin 2 \Theta_{X}}{\left(C_{11}-C_{44}\right) \cos ^{2} \Theta_{X}+\left(C_{44}-C_{33}\right) \sin ^{2} \Theta_{X}}, \\
& \zeta_{Y Z}=\frac{1}{2} \arctan \frac{\left(C_{13}+C_{44}\right) \sin 2 \Theta_{Y}}{\left(C_{11}-C_{44}\right) \cos ^{2} \Theta_{Y}+\left(C_{44}-C_{33}\right) \sin ^{2} \Theta_{Y}}, \\
& \zeta_{X Y}=\frac{1}{2} \arctan \frac{\left(C_{11}+C_{66}\right) \sin 2 \Theta_{X}}{\left(C_{11}-C_{66}\right) \cos 2 \Theta_{X}} .
\end{aligned}
$$

In Eqs. (2)-(4), $\Theta_{X}$ (or $\Theta_{Y}$ ) denotes the angle between the AW vector and the $X$ (or $Y$ ) axis. The non-orthogonality of quasi-transverse (QT) AWs can be calculated using the same formulae. The only difference is that a factor of 90 deg should be added to the r. h. s. of Eqs. (4)-(6). 

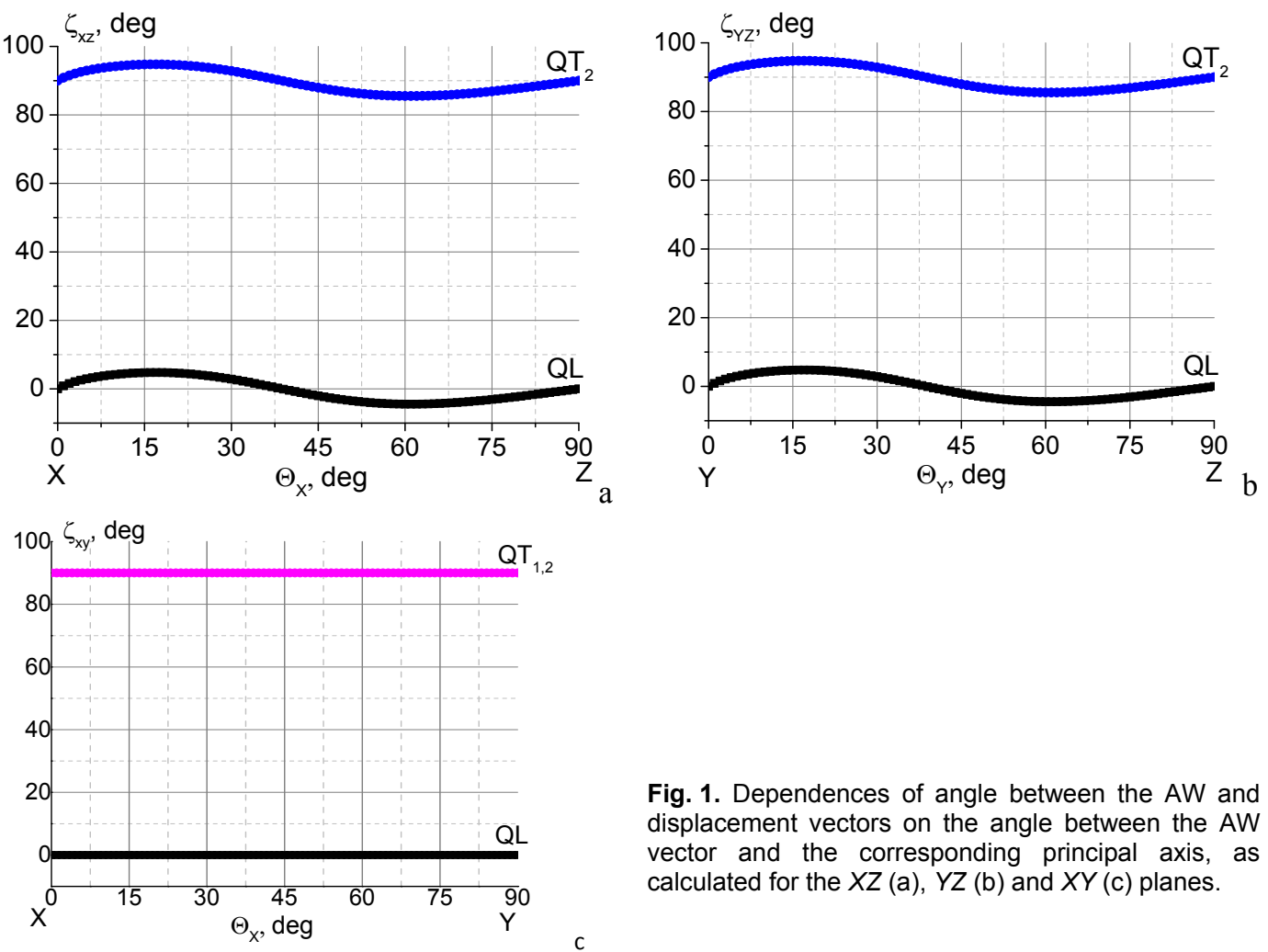

Fig. 1. Dependences of angle between the AW and displacement vectors on the angle between the AW vector and the corresponding principal axis, as calculated for the $X Z(a), Y Z(b)$ and $X Y(c)$ planes.

As seen from Fig. 1, the angle of deviation of the acoustic polarizations from their purely longitudinal and transverse types is very low for the $\mathrm{CdS}$ crystals. Its maximum value, $\sim 4.7 \mathrm{deg}$, is reached when the AW propagates in the $X Z$ or $Y Z$ planes along the direction inclined by $17 \mathrm{deg}$ with respect to the $X$ or $Y$ axes, respectively. The AWs remain purely longitudinal or purely transverse while propagating in the principal $X Y$ plane. This means that, in our further analysis of the AOFM anisotropy, we can neglect both the non-orthogonality effect and the deviation from the purely longitudinal AW types.

It is well known that the AOFM is given by the relation [29]

$$
M_{2}=\frac{n_{i}^{3} n_{d}^{3} p_{e f}^{2}}{\rho v^{3}},
$$

where $n_{i}$ and $n_{d}$ are the refractive indices of the incident and diffracted optical waves, $p_{e f}$ denotes the effective elastooptic coefficient (EEC), $v$ the phase AW velocity, and $\rho$ the material density $\left(\rho=4820 \mathrm{~kg} / \mathrm{m}^{3}\right.$ [19]). The refractive indices and the EEC in the anisotropic media depend on the propagation direction and the polarization of both incident and diffracted optical waves [10]. In the case of collinear AO interactions, the parameter $n_{d}=n^{*}{ }_{e}$ in Eq. (5) depends on the angle $\Theta$ via

$$
n_{e}=\frac{n_{e} n_{o} \sqrt{n_{e}^{2} \sin ^{2} \Theta+n_{o}^{2} \cos ^{2} \Theta}}{n_{e}^{2} \sin ^{2} \Theta+n_{o}^{2} \cos ^{2} \Theta} .
$$

In order to obtain the angular dependence of AOFM, we apply a method used in our recent works for the case of anisotropic diffraction $[16,30]$. The initial interaction plane parallel to the $X Z$ plane is then rotated by $\varphi_{Z}$ around the $Z$ axis. Using such rotations, one can run through all 
possible geometries of the collinear AO interactions in optically uniaxial crystals. The AW velocities for every propagation direction can be obtained from a standard Christoffel equation. For the interaction planes rotated by some angle $\varphi_{Z}$ around the $Z$ axis, we rewrite the elastic stiffness tensor in a new coordinate system $X^{\prime} Y^{\prime} Z$ such that its structure remains the same for the symmetry group $6 \mathrm{~mm}$.

According to our classification [30], in our case we deal with the types VII, VIII and IX of anisotropic AO interactions. The type VII corresponds to AO interactions with the AW QL. The relation for the EEC for this interaction type is as follows:

$$
\begin{aligned}
p_{e f}^{(\mathrm{VII})} & =\left\{\begin{array}{l}
\left(p_{11} \cos ^{2} \varphi_{Z} \cos ^{2} \Theta+p_{12} \sin ^{2} \varphi_{Z} \cos ^{2} \Theta+p_{13} \sin ^{2} \Theta\right) \sin \Theta \cos \varphi_{Z}- \\
\left(p_{66} \cos ^{2} \Theta \sin 2 \varphi_{Z}\right) \sin \Theta \sin \varphi_{Z}- \\
\left(p_{55} \cos \varphi_{Z} \sin 2 \Theta\right) \cos \Theta
\end{array}\right\} \sin \varphi_{Z} \\
& -\left\{\begin{array}{l}
\left(-p_{66} \cos ^{2} \Theta \sin 2 \varphi_{Z}\right) \sin \Theta \cos \varphi_{Z}+ \\
\left.\left(p_{21} \cos ^{2} \varphi_{Z} \cos ^{2} \Theta+p_{11} \sin ^{2} \varphi_{Z} \cos ^{2} \Theta+p_{13} \sin ^{2} \Theta\right) \sin \Theta \sin \varphi_{Z}+\right\} \cos \varphi_{Z} . \\
\left(p_{44} \sin \varphi_{Z} \sin 2 \Theta\right) \cos \Theta
\end{array}\right\}
\end{aligned}
$$

For the type VIII of interactions with the $\mathrm{AW} \mathrm{QT}_{1}$ propagating with the velocity $v_{13}$, we obtain

$$
\begin{aligned}
p_{e f}^{\text {(VIII) }} & =\left\{\begin{array}{l}
\left(p_{13}-p_{11} \cos ^{2} \varphi_{Z}-p_{12} \sin ^{2} \varphi_{Z}\right) \sin 2 \Theta \sin \Theta \cos \varphi_{Z}+ \\
\left(p_{66} \sin 2 \Theta \sin 2 \varphi_{Z}\right) \sin \Theta \sin \varphi_{Z}- \\
\left(p_{55} \cos 2 \Theta \cos \varphi_{Z}\right) \cos \Theta
\end{array}\right) \sin \varphi_{Z}- \\
& -\left\{\begin{array}{l}
\left(p_{66} \sin 2 \Theta \sin 2 \varphi_{Z}\right) \sin \Theta \cos \varphi_{Z}+ \\
\left.\left(p_{13}-p_{12} \cos ^{2} \varphi_{Z}+p_{11} \sin ^{2} \varphi_{Z}\right) \sin 2 \Theta \sin \Theta \sin \varphi_{Z}+\right\} \cos \varphi_{Z}, \\
\left(p_{44} \cos 2 \Theta \sin \varphi_{Z}\right) \cos \Theta
\end{array}\right)
\end{aligned}
$$

while, for the collinear $\mathrm{AO}$ interactions with the $\mathrm{AW} \mathrm{QT}_{2}$ propagating with the velocity $v_{12}$, the EEC is given by

$$
\begin{aligned}
p_{e f}^{(\mathrm{IX})} & =\left\{\begin{array}{l}
{\left[\left(p_{11}-p_{12}\right) \sin 2 \varphi_{Z} \cos \Theta\right] \sin \Theta \cos \varphi_{Z}+} \\
\left(p_{66} \cos 2 \varphi_{Z} \cos \Theta\right) \sin \Theta \sin \varphi_{Z}- \\
\left(p_{55} \sin \Theta \sin \varphi_{Z}\right) \cos \Theta
\end{array}\right] \sin \varphi_{Z}- \\
& -\left\{\begin{array}{l}
\left(p_{66} \cos 2 \varphi_{Z} \cos \Theta\right) \sin \Theta \cos \varphi_{Z}+ \\
{\left[\left(p_{12}-p_{11}\right) \sin 2 \varphi_{Z} \cos \Theta\right] \sin \Theta \sin \varphi_{Z}-} \\
\left(p_{44} \sin \Theta \cos \varphi_{Z}\right) \cos \Theta
\end{array}\right\} \cos \varphi_{Z} .
\end{aligned}
$$

Inside the cone of acoustic axes, i.e. between the angles equal to 14 and $166 \mathrm{deg}$ and 194 and $346 \mathrm{deg}$ the Eqs. 8 and 9 should be interchanged, since the polarization of eigen AWs is switched on $90 \mathrm{deg}$ at the angular passing by the wave vector the directions of outlets of acoustic axes (see below).

\section{Results and discussion}

\subsection{Acoustic anisotropy}

Although CdS is hexagonal, its elastic properties are rather isotropic. As seen from Fig. 2a and Fig. 2b, the velocities of the AWs QL and QT manifest only a weak dependence on the AW propagation direction in the $X Z$ plane. In the $X Y$ plane, these velocities lack any anisotropy altogether. Rotation of the interaction plane around the $Z$ axis does not change the cross sections of the AW velocities surfaces (see Fig. 3). The velocities of the AWs QT become equal for all the 
propagation directions parallel to the generating lines of the cone of which revolution axis is parallel to the $Z$ axis, as well as to the $Z$ axis itself. The angle at the vertex of this cone is equal to $152 \mathrm{deg}$. In other words, the generating lines of the cone and the $Z$ axis represent the acoustic axes for the CdS crystals (see Fig. 2a, c and Fig. 3b, c).
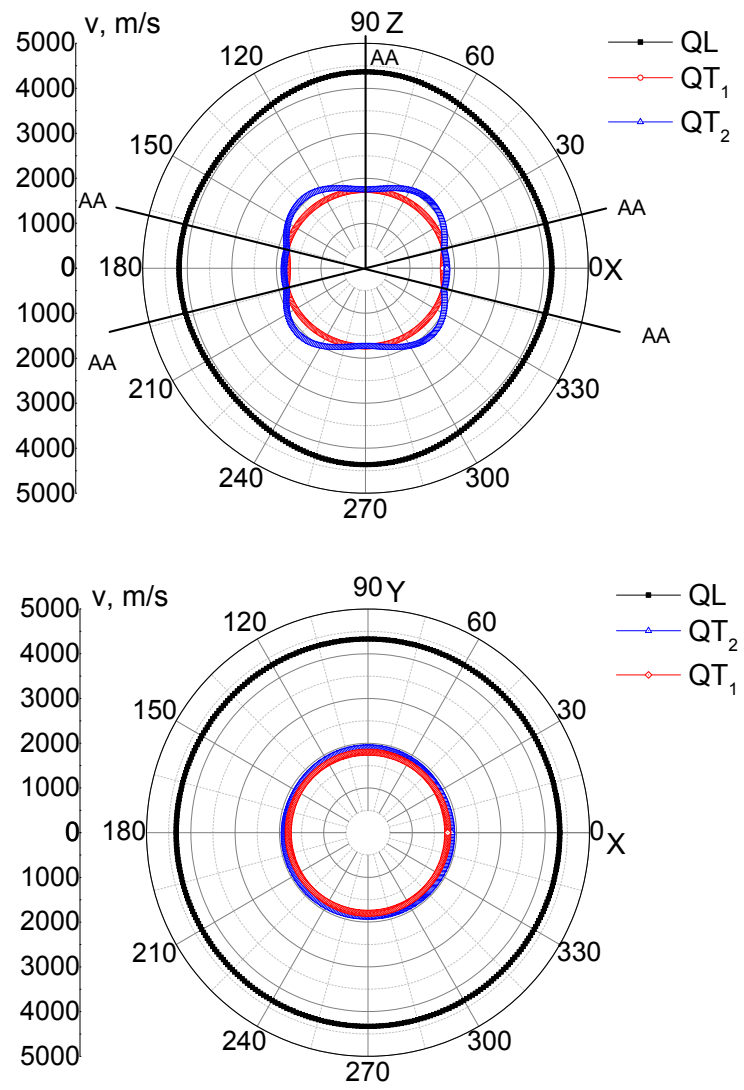

(a)

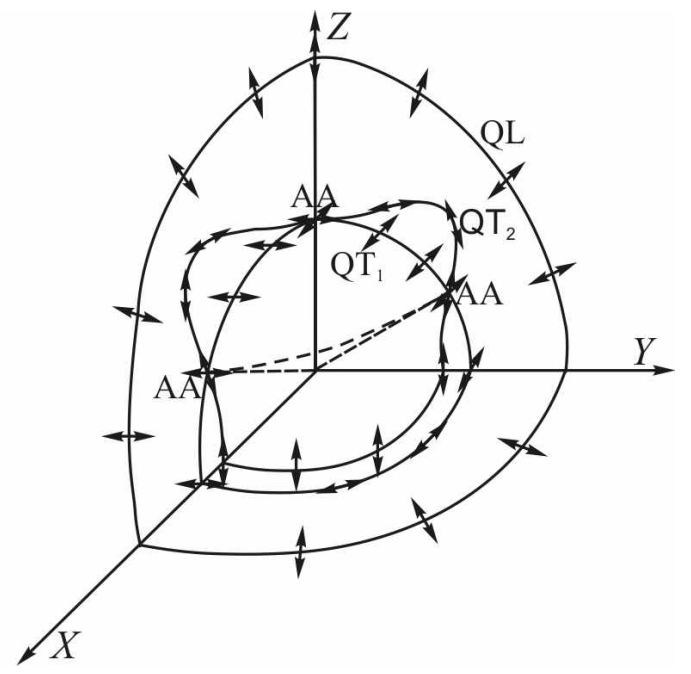

(b)

(c)

Fig. 2. Dependences of $A W$ velocity on the $A W$ propagation direction $\Theta$ in $X Z$ (a) and $X Y$ planes (b): $A A$ denote outlets of the acoustic axes. c - AW surfaces for CdS crystals, with indication of polarizations of acoustic eigenwaves by double-sided arrows.

Ukr. J. Phys. Opt. 2018, Volume 19, Issue 3 


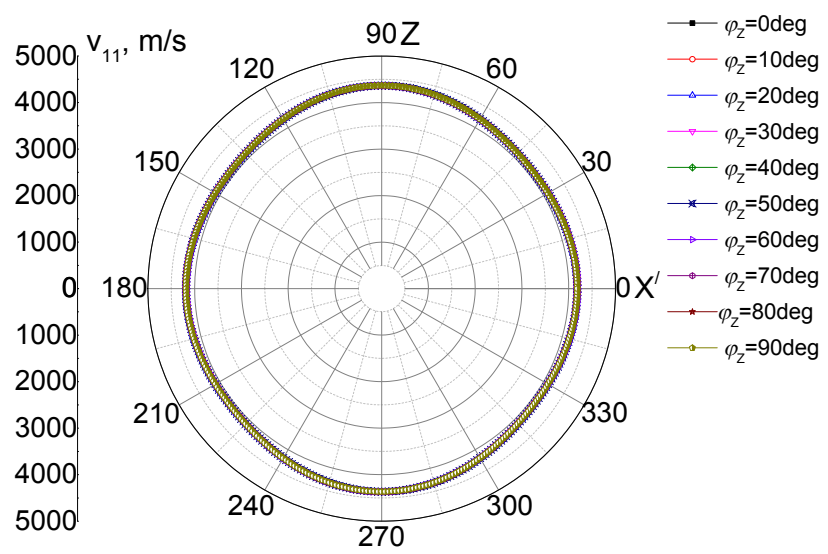

(a)

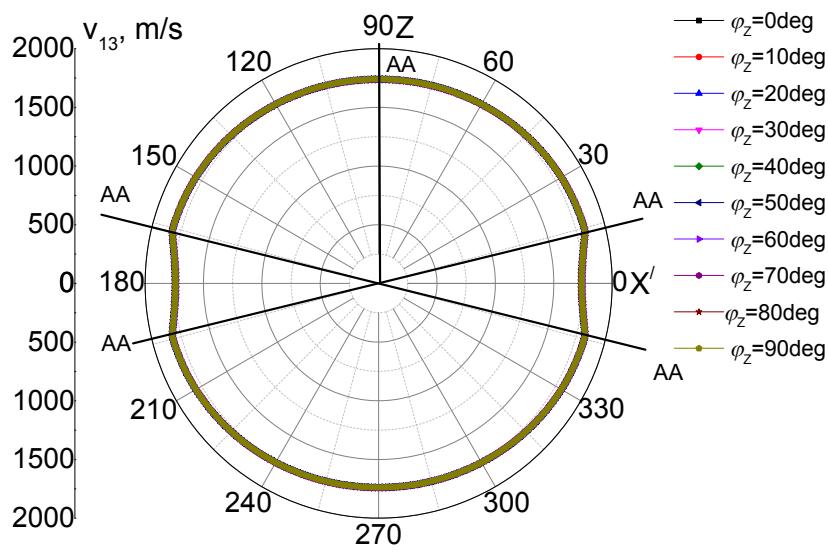

(b)

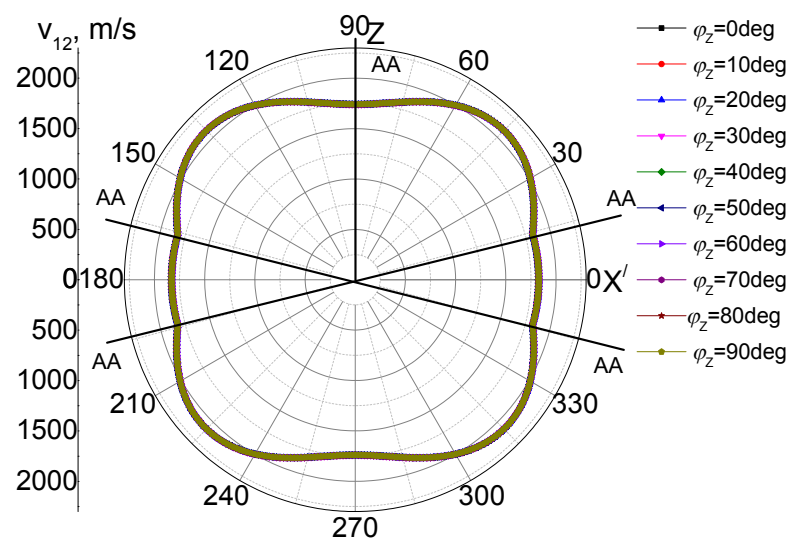

(c)

Fig. 3. Dependences of $A W$ velocities on the angle $\Theta$ in the $X Z$ plane at different angles $\varphi_{Z}$, as calculated for the AWs QL (a), $Q T_{1}(b)$ and $Q T_{2}$ (c): AA denote outlets of the acoustic axes.

Rotations of the interaction plane around the $X$ axis hardly changes the cross sections of the AW velocities (see Fig. 4). Therefore, the anisotropy of the AW velocities in CdS cannot affect sufficiently the AOFM anisotropy.

A low enough anisotropy of AW velocities in CdS results in small deviations of the acoustic energy flow $\Delta$ from the AW vector. Dependences of the obliquity angle $\Delta$ on the direction of AW propagation in the $X Z$ plane are shown in Fig. 5. The maximum obliquity amounts to 
$\Delta_{\max }^{\mathrm{QL}}=6.3 \mathrm{deg}$ for the $\mathrm{QL}$ wave. This corresponds to the AW propagation direction inclined by the angle $\Theta=62$ deg with respect to the $X$ axis in the $X Z$ plane. The deviation of the acoustic energy flow from the $\mathrm{AW}$ vector reaches higher values for the $\mathrm{QT}_{2}$ waves. In particular, we have $\Delta_{\max }^{\mathrm{QT2}}=20.7 \mathrm{deg}$ (the $X Z$ plane; $\Theta=21 \mathrm{deg}$ with respect to the $X$ axis). For the $\mathrm{AW} \mathrm{QT}_{1}$, we have $\Delta_{\max }^{\mathrm{QT1}}=18.6$ deg for the $X Z$ plane and the angle $\Theta=14^{\circ}$ with respect to the $X$ axis. Finally, the obliquity angle remains zero when the AWs propagate in the $X Y$ plane.

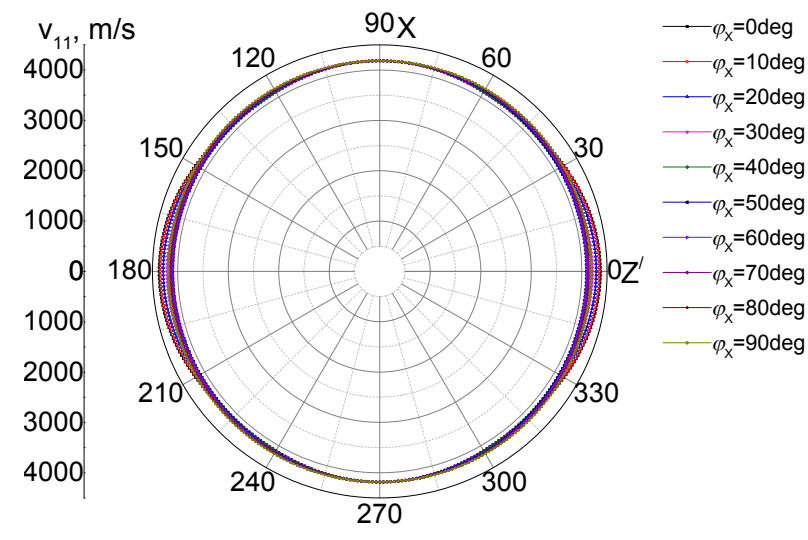

(a)

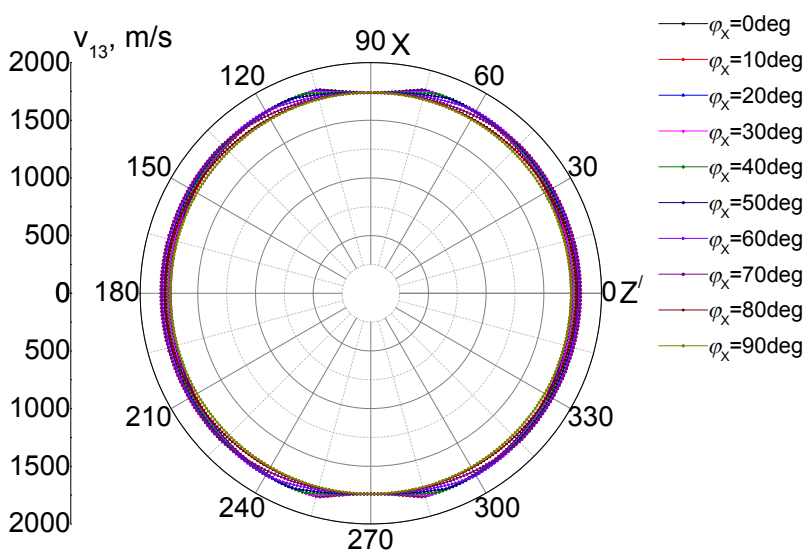

(b)

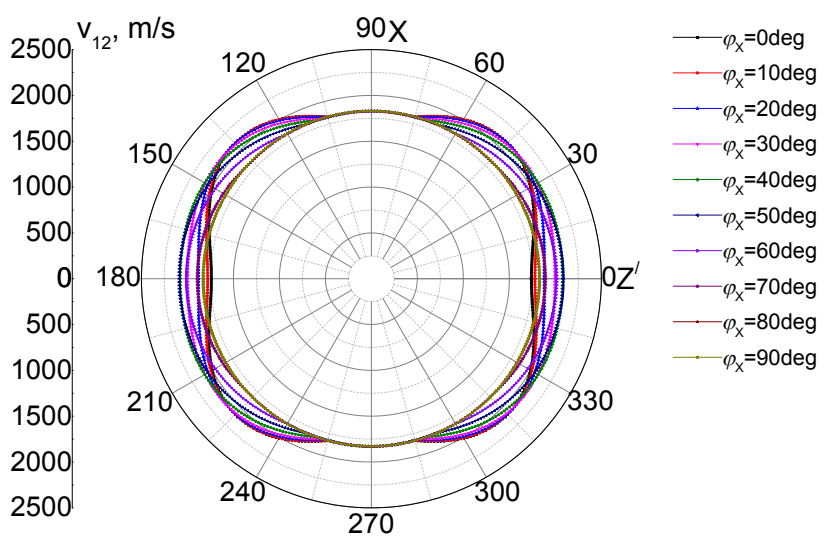

(c)

Fig. 4. Dependences of $A W$ velocities on the angle $\Theta$ in the $X Z^{\prime}$ plane rotated by different angles $\varphi_{x}$, as calculated for the AWs QL (a), $\mathrm{QT}_{1}(\mathrm{~b})$ and $\mathrm{QT}_{2}$ (c).

Ukr. J. Phys. Opt. 2018, Volume 19, Issue 3 


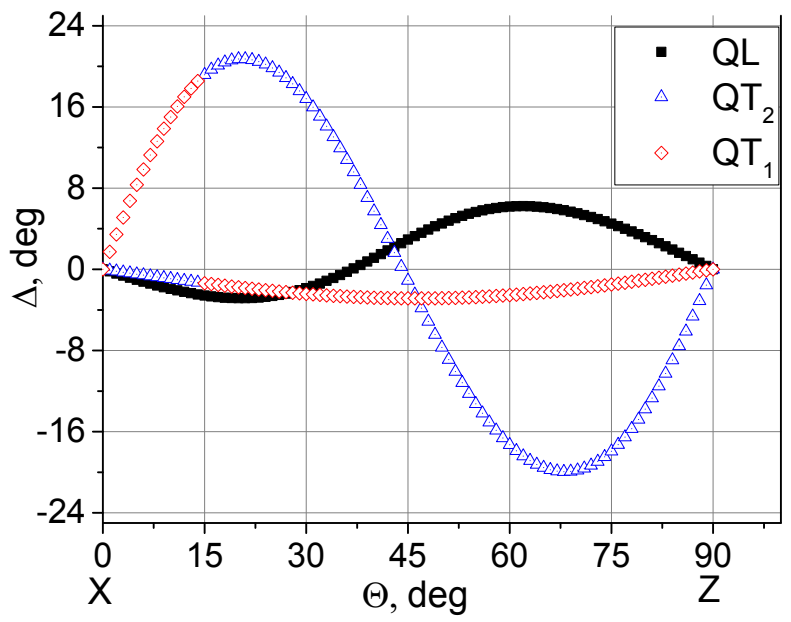

Fig. 5. Dependence of obliquity angle $\Delta$ on the AW propagation direction $\Theta$ in the $X Z$ plane.

\subsection{Anisotropy of collinear acousto-optic interactions}

The anisotropies of the EEC and the AOFM for the type VII of AO interactions with the AW QL are displayed in Fig. 6. Here the AOFM anisotropy arises due to anisotropic EEC. The maximal AOFM for this type of AO interactions is not so high $\left(M_{2}=4.41 \times 10^{-15} \mathrm{~s}^{3} / \mathrm{kg}-\right.$ see Fig. $\left.6 \mathrm{~b}\right)$. This value is reached in the interaction plane $X^{\prime} Z$ rotated around the $Z$ axis by the angles $\varphi_{Z}=50$ or $130 \mathrm{deg}$ and at the angles of incidence $\Theta=35,145,215$ and $325 \mathrm{deg}$. The AW frequency providing the type VII of collinear $\mathrm{AO}$ interactions is equal to $f=71 \mathrm{MHz}$.

For the type VIII of collinear AO interactions with the AW QT ${ }_{1}$, the AOFM is very large (see Fig. 7), which is mostly due to low AW velocity. Here the AOFM anisotropy is caused by the EEC anisotropy (Fig. 7a). As seen from Fig. 7b, the absolute AOFM maximum is equal to $M_{2}=86.26 \times 10^{-15} \mathrm{~s}^{3} / \mathrm{kg}$. This value is peculiar for the interaction plane rotated by the angle $\varphi_{Z}=45 \mathrm{deg}$. Then both the optical waves and the AWs propagate along the $X^{\prime}$ axis lying in the $X Y$ plane (i.e., $\Theta=0 \mathrm{deg}$ ). Notice that the obliquity angle for the type VIII of interactions is zero (see Fig. 5). Finally, the AW frequency providing these interactions is equal to $f=49 \mathrm{MHz}$.

Under collinear interactions with the fast shear $\mathrm{AW} \mathrm{QT}$ (i.e., the type IX of $\mathrm{AO}$ interactions), the maximal AOFM is equal to $M_{2}=57 \times 10^{-15} \mathrm{~s}^{3} / \mathrm{kg}-$ see Fig. $8 \mathrm{~b}$ ). This value is reached in the interaction plane $X^{\prime} Z$ rotated around the $Z$ axis by the angles $\varphi_{Z}=45$ and at the angles of incidence $\Theta=14,166,195$ and $346 \mathrm{deg}$. In all of the cases mentioned above, the EEC anisotropy makes the main impact on the anisotropy of AOFM (see Fig. 8a). The obliquity angle is high enough for the latter type of collinear AO interactions. Hence, the obliquity angle of the acoustic energy flow is equal to $\sim 19 \mathrm{deg}$ for the geometry of $\mathrm{AO}$ interactions that corresponds to the highest AOFM value (see Fig. 5). The AW frequency providing this collinear interaction type is equal to $f=46 \mathrm{MHz}$.

Summarizing the results obtained above, we conclude that the anisotropy of EEC does enable suitable conditions under which the AOFM reaches its highest value at the collinear AO interactions. It is worthwhile that the acoustic attenuation of CdS in the frequency region of tens of $\mathrm{MHz}$ is not so high. Hence, CdS can be efficiency used in operative elements for both integrated optical and bulk optical AO applications. 


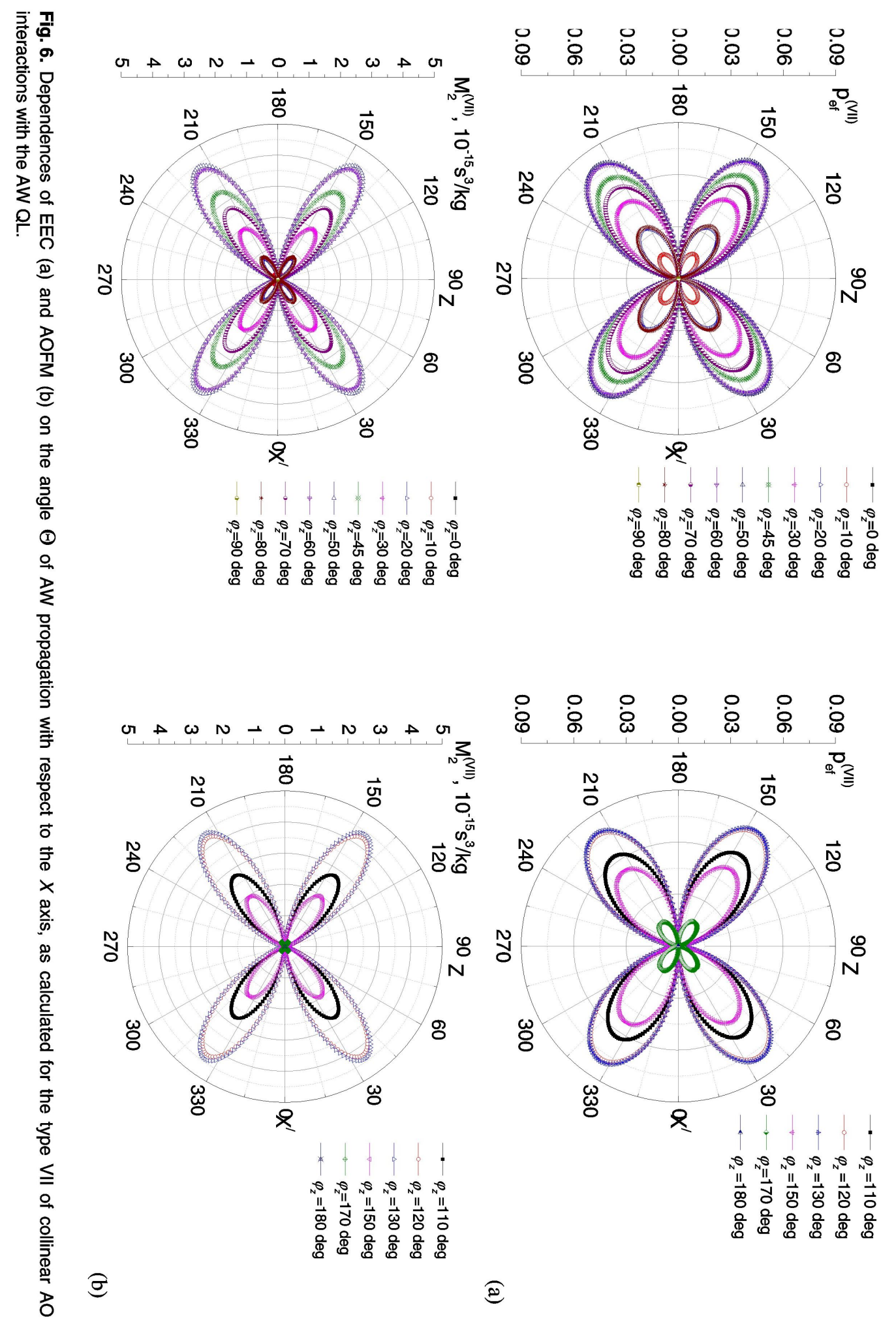

Ukr. J. Phys. Opt. 2018, Volume 19, Issue 3 


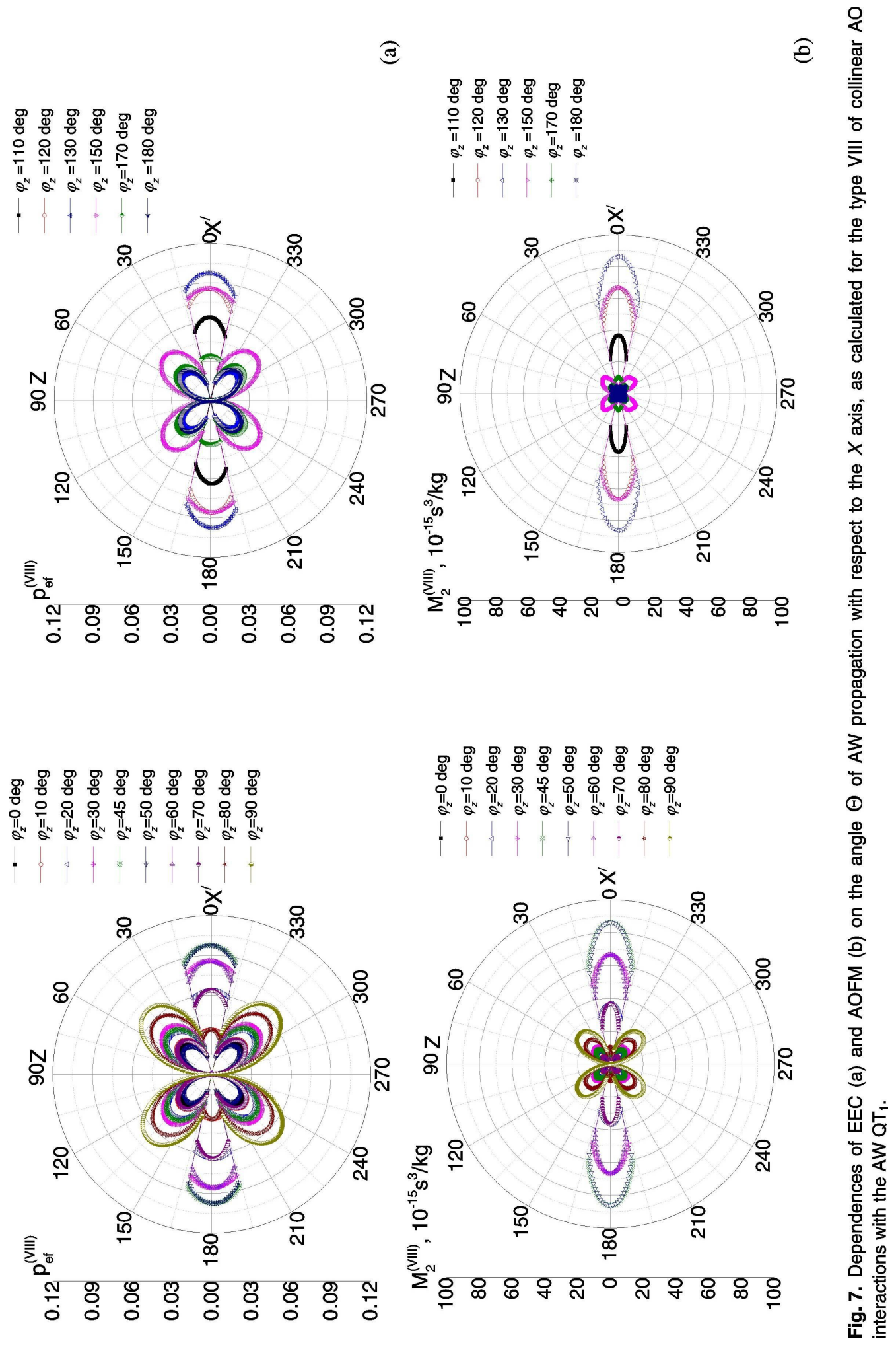




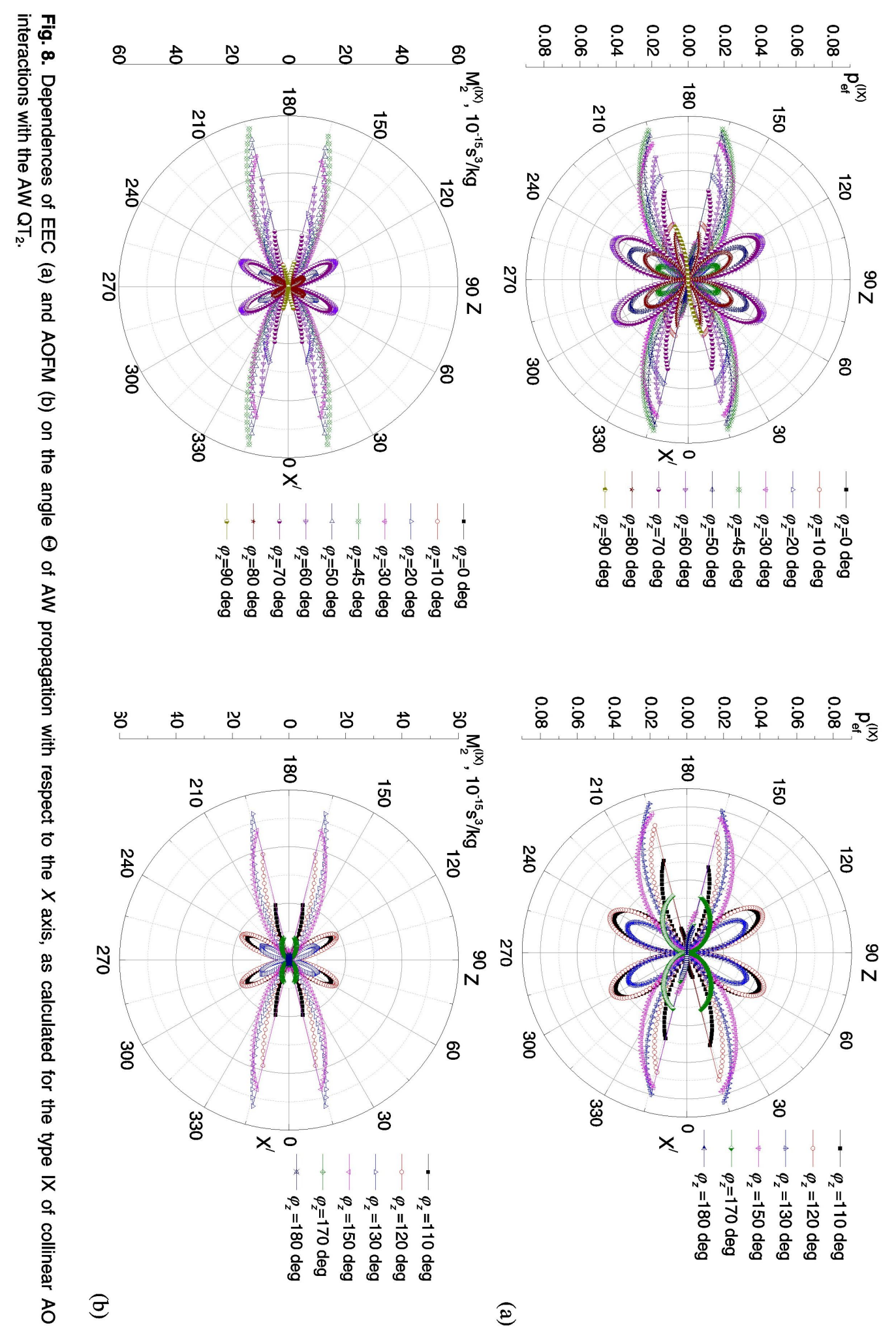

Ukr. J. Phys. Opt. 2018, Volume 19, Issue 3 


\section{Conclusion}

We analyze the anisotropy of AOFM at the collinear acoustoopic interactions occurring in CdS. It is shown that the anisotropy of AW velocity is small and the AOFM anisotropy is mainly caused by the anisotropy of EEC. We find that the crystals under study have the acoustic axes parallel to the $Z$ direction and the directions within the cone of which revolution axis coincides with the $Z$ axis. The angle at the vertex of this cone is equal to $152 \mathrm{deg}$. We demonstrate that deviations from the purely transverse and longitudinal AWs types are rather small for CdS. The maximum obliquity angle, $\Delta_{\max }^{\mathrm{QT1}}=20.7 \mathrm{deg}$, is peculiar for the $\mathrm{AW} \mathrm{QT}_{1}$. Our analysis made for the case of collinear AO interactions of the optical waves with the AW QL and both the slow and fast AWs QT has revealed the diffraction geometries at which maximal AOFM values can be reached. The absolute maximum of the AOFM, $M_{2}=86.26 \times 10^{-15} \mathrm{~s}^{3} / \mathrm{kg}$, is typical for the type VIII of AO interactions with the $\mathrm{AW} \mathrm{QT}_{1}$ of the frequency $f=49 \mathrm{MHz}$, which is polarized along the $Z$ axis. Then the interaction plane is rotated by the angle $\varphi_{Z}=45 \mathrm{deg}$, while the light and the AW propagate along the $X^{\prime}$ axis lying in the $X Y$ plane. The maximal AOFM values and the corresponding interaction geometries are determined for the cases of collinear AO diffraction at the AWs QL and $\mathrm{QT}_{2}$. These values are equal to $4.41 \times 10^{-15}$ and $26.25 \times 10^{-15} \mathrm{~s}^{3} / \mathrm{kg}$ for the interactions with the AWs QL and $\mathrm{QT}_{2}$, respectively.

\section{Acknowledgement}

The authors acknowledge financial support of the present study from the Ministry of Education and Science of Ukraine (the Project \#0118U003899).

\section{References}

1. Frondel C and Palache C, 1950. Three new polymorphs of zinc sulfide. Amer. Mineral. 35: $29-42$.

2. Shaskolskaya M P. Acoustic crystals. Moscow: Nauka, 1982.

3. Francis A B and Carlson A I, 1960. Cadmium sulfide infrared optical material. J. Opt. Soc. Amer. 50: 118-121.

4. Berlincourt D, Jaffe H, and Shiozawa L R, 1963. Electroelastic properties of the sulfides, selenides, and tellurides of zinc and cadmium. Phys. Rev. 129: 1009-1017.

5. Spear W E and Mort J, 1963. Electron and hole transport in CdS crystals. Proc. Phys. Soc. 81: $130-140$

6. Kaminow J P and Turner E H. Handbook of lasers. Ed. by Pressley R J. Cleveland: The Chemical Rubber Co. 1971.

7. Zhengang Li, Guangnan Xiong, Zhihong Zhao, Xiwu Fan, 1994. Measurement of optical nonlinear susceptibility of CdS single crystal using a single beam. J. Cryst. Growth. 138: 231233.

8. Gainon D J A, 1964. Linear electro-optic effect in CdS. J. Opt. Soc. Amer. 54: 270-271.

9. Sugie V and Tada K, 1976. Measurements of the linear electrooptic coefficients and analysis of the nonlinear susceptibilities in cubic GaAs and hexagonal CdS. Japan. J. Appl. Phys. 15: $421-432$.

10. Kawabe V, Kotani H, Masuda K and Namba S, 1975. Heterostructure $\mathrm{CdS}_{1-\mathrm{x}} \mathrm{Se}_{\mathrm{x}}-\mathrm{CdS}$ surface lasers for integrated optics. Appl. Phys. Lett. 26: 46-48.

11. Buachidze É É, Vasilishcheva I V, Morozov V N, Pletnev V A, Semenov A S and Shapkin P $\mathrm{V}$, 1986. Fabrication and investigation of integrated-optics $\mathrm{CdS}_{\mathrm{x}} \mathrm{Se}_{1-\mathrm{x}}$ waveguides. Sov. J. Quant. Electron. 16: 1201-1204. 
12. Tao Liu, Peng Liu, Lian Zhang, Yu-Fan Zhou, Xiao-Fei Yu, Qing Huang, Qing-Ming Lu and Xue-Lin Wang, 2014. Planar and channel waveguide structures in CdS crystals at 633 and 1539 nm. J. Lightwave Technol. 32: 2556-2559.

13. Dixon R W, 1967. Photoelastic properties of selected materials and their relevance for applications to acoustic light modulators and scanners. J. Appl. Phys. 38: 5149-5153.

14. Mys O, Kostyrko M, Krupych O and Vlokh R, 2015. Anisotropy of the acousto-optic figure of merit for $\mathrm{LiNbO}_{3}$ crystals: isotropic diffraction. Appl. Opt. 54: 8176-8186.

15. Mys O, Kostyrko M and Vlokh R, 2016. Anisotropy of acousto-optic figure of merit for $\mathrm{LiNbO}_{3}$ crystals: anisotropic diffraction. Appl. Opt. 55: 2439-2450.

16. Mys O, Krupych O, Kostyrko M and Vlokh R, 2016. Anisotropy of acousto-optic figure of merit for $\mathrm{LiNbO}_{3}$ crystals: anisotropic diffraction. Erratum. Appl. Opt. 55: 9823-9829.

17. Bateman T B and McFee J H, 1968. Nonelectronic ultrasonic attenuation in CdS. J. Appl. Phys. 39: 4471-4472.

18. Buachidze Z É, Goldobin I S, Morozov V N, Pletnev V A, Semenov A S and Shapkin P V, 1986. Waveguide Bragg light modulators made of $\mathrm{CdS}_{\mathrm{x}} \mathrm{Se}_{1-\mathrm{x}}$ crystals. Sov. J. Quant. Electron. 16: $456-458$.

19. Gerlich D, 1967. The elastic constants of cadmiumsulfide between $4.2-300^{\circ} \mathrm{K}$. J. Phys. Chem. Sol. 28: 2575-2579.

20. Vedam K and Davis T A, 1969. Pressure dependence of the refractive indices of the hexagonal crystals beryl, $\alpha-C d S, \alpha-Z n S$, and ZnO. Phys. Rev. 181: 1196-1201.

21. Ward J, Farries M, Pannell C and Wachman E, 2010: p.78350U-78350U-9. An acousto-optic based hyperspectral imaging camera for security and defense applications. Retrieved from: http://proceedings.spiedigitallibrary.org/proceeding.aspx?articleid=1347890

22. Tran Chieu D and Furlan Ricardo J, 1992. Acousto-optic tunable filter as a polychromator and its application in multidimensional fluorescence spectrometry. Anal. Chem. 64: 2775-2782.

23. Valle S, Ward J D, Pannell C and Johnson N P, 2015. Acousto optic tunable filters for imaging applications in the $2-4 \mu \mathrm{m}$ with low RF drive power. Acta Phys. Polon. A. 127: 5859.

24. Chang I C, 1977. Tunable acousto-optic filters: an overview. Opt. Eng. 16: 455-460.

25. Voloshinov V B, 1992. Close to collinear acousto-optical interaction in $\mathrm{TeO}_{2}$ single crystal. In: Acousto-Optics and Applications. Int. Soc. Opt. Photon. p. 162-176.

26. Bieniewski T M and Czyzak S J, 1963. Refractive indexes of single hexagonal $\mathrm{ZnS}$ and CdS crystals. J. Opt. Soc. Amer. 53: 496-497.

27. Sirotin Yu I and Shaskolskaya M P. Fundamentals of crystal physics. Moscow: Mir, 1982.

28. Ohmachi Y, Uchida $\mathrm{N}$ and Niizeki N, 1972. Acoustic wave propagation in $\mathrm{TeO}_{2}$ single crystal. J. Acoust. Soc. Amer. 51: 164-168.

29. Balakshyi V I, Paryhyn V N and Chyrkov L E. Basic physics of acoustooptics. Moscow: Radio i Svyaz, 1985.

30. Mys O, Krupych O and Vlokh R, 2016. Anisotropy of an acousto-optic figure of merit for $\mathrm{NaBi}\left(\mathrm{MoO}_{4}\right)_{2}$ crystals. Appl. Opt. 55: 7941-7955.

Mys O., Martynyuk-Lototska I., Adamenko D., Kostyrko M. and Vlokh R. 2018. Anisotropy of acousto-optic figure of merit at the collinear acousto-optic diffraction in hexagonal CdS crystals. Ukr.J.Phys.Opt. 19: 165 - 178. doi: 10.3116/16091833/19/3/165/2018

Анотація. Проаналізовано анізотропію акустичних властивостей $i$ коефіцієнта акустооптичної якості (КАОЯ) для кристалів CdS за умови колінеарної дифракцї. 
Показано, щчо анізотропія швидкостей акустичних хвиль (АХ) досить слабка, а тому анізотропія КАОЯ в основному зумовлена анізотропією ефективних пружно-оптичних коефіиієнтів. Отримано кути зносу енергії АХ та кути відхилення їхньої поляризації від суто поздовжнього та поперечного станів поляризації. Визначено геометрії, за яких можна досягти максимальних значень КАОЯ для колінеарної дифракиії. Встановлено, щзо абсолютний максимум КАОЯ $\left(M_{2}=86,26 \times 10^{-15} c^{3} / \kappa 2\right)$ притаманний типу VIII взаємодій із $A X Q T_{1}$, яка має частоту $f=49$ МГи і поляризована вздовж осі $Z$. Тоді площина взаємодї повернута на кут $\varphi_{Z}=45$ град, а обидві оптичні та акустична хвилі поширюються вздовж осі $X$, щзо лежить у площчні ХY. Визначено максимальні значення КАОЯ $i$ відповідні геометрії взаємодій для випадків колінеарної дифракції на $A X Q L$ i $Q T_{2}$. Ці значення становлять $4.41 \times 10^{-15}$ і $26.25 \times 10^{-15} \mathrm{c}^{3} /$ кг відповідно для взаємодій із AX QL i $Q T_{2}$. 